\title{
Development of Methodological Bases of the Processes of Steam Formation in Coil Type Boilers Using Solar Concentrators
}

\author{
Konstantin Osintsev (D), Sergei Aliukov*(D) and Sulpan Kuskarbekova \\ Institute of Engineering and Technology, South Ural State University, 454080 Chelyabinsk, Russia; \\ osintcevkv@susu.ru (K.O.); kuskarbekovasi@susu.ru (S.K.) \\ * Correspondence: dimaakv@yandex.ru
}

Citation: Osintsev, K.; Aliukov, S.; Kuskarbekova, S. Development of Methodological Bases of the Processes of Steam Formation in Coil Type Boilers Using Solar Concentrators. Energies 2021, 14, 2333. https://doi.org/10.3390/en14082333

Academic Editor: Antonio Calvo Hernández

Received: 10 March 2021

Accepted: 15 April 2021

Published: 20 April 2021

Publisher's Note: MDPI stays neutral with regard to jurisdictional claims in published maps and institutional affiliations.

Copyright: (c) 2021 by the authors. Licensee MDPI, Basel, Switzerland. This article is an open access article distributed under the terms and conditions of the Creative Commons Attribution (CC BY) license (https:// creativecommons.org/licenses/by/ $4.0 /)$.

\begin{abstract}
A mathematical model of the vaporization process in the coil is developed, taking into account the experimental data. To investigate and visualize the evaporation procedure in the coil, a mathematical pattern of the vapor-liquid mixture motion is compiled and reproduced. In the methodology of the study of the movement of the steam-water mixture, correction coefficients are proposed for calculating the velocities of the coolant in non-standard coaxial coils. The parameters were calculated using data sensitivity analysis and data validation was performed by repeated tests; uncertainty was detected when using the instruments, as well as the total extended uncertainty, the upper and lower limit of uncertainty for each measured parameter. In addition, as part of the steam generator set, solar collectors operate in the summer mode. Using the example of the studied steam generator operating in the conditions of an oil and gas field in the subarctic climate, it is shown that it is possible to use air-type solar collectors for the ventilation system of the production room, as well as water-heating solar collectors for technical systems of hot water supply and chemical water treatment.
\end{abstract}

Keywords: boiler installation; coaxial cylinders; coil pipe; heat transfer; solar concentrators

\section{Introduction}

\subsection{Relevance of the Research Topic}

At present, a reliable autonomous energy supply is an urgent practical task for oil and gas fields located in the arctic and subarctic climates. This applies to the industrial part of drilling rigs, as well as the domestic part of the premises where working specialists live. It should be noted that the development of new fields is impossible without the construction of heat and electricity sources. Since the newly developed fields are located at a considerable distance from the centralized power grids, the only option remains the construction of steam boilers that generate steam for the drilling rig and an autonomous power supply source. The source of electricity supply can be a gas turbine plant or renewable energy sources. As for providing heat to domestic premises, here in the case of a steam boiler unit, heat exchangers are installed for heating cold water and recently for the summer period, tanks for heating water based on renewable energy sources.

\subsection{Solving a Scientific Problem}

The generated steam under the operating conditions of the drilling rig must be of low or medium pressure and be in an overheated state. Many types of steam installations can produce steam with such parameters. On the territory of oil fields in Siberia, there are often block-modular transportable boiler installations on the basis of boilers E-1.0-0.9 M (Z), which run on fluid propellant. The propellant consumption in the rated mode is $0.28 \mathrm{~kg} / \mathrm{s}$. The working pressure of the coolant at the outlet of the boiler is on average $0.75-0.8 \mathrm{MPa}$ at a temperature of $174.5^{\circ} \mathrm{C}(447.65 \mathrm{~K})$. However, these boiler units have low efficiency and 
low reliability of operation. In this regard, new fields are trying to introduce new types of steam generator that would meet the requirements of the drilling rig, but at the same time work more reliably and efficiently. One of these types of boilers is a direct-flow steam generator of the coil type. Similar boilers and heat exchangers are known in the industry, but for working conditions at extremely low temperatures, previous experiments have not been conducted anywhere in the world.

\subsection{Review of Scientific Research on the Topic of the Work}

The interest in the study of hydrodynamic and thermal processes in coil-shaped heat exchange elements can be traced by authors from different countries. In [1], a numerical simulation of heat transfer is performed on the example of a coil heat exchanger in relation to a reactor installation. Special attention is paid to the comparison of the results obtained using different turbulence models, as well as to the study of the influence of the structure of the calculated grid. In the articles, studies have been carried out for single-phase and two-phase flows, as well as for coiled and spiral-coiled pipes [2,3]. The results of foreign scientific activities devoted to heat exchange processes, including those that take into account non-stationary phenomena, are presented both in numerical and experimental works. The authors of the publications $[4,5]$ conducted a computational and experimental study on the example of a spiral heat exchange element, comparing the results of numerical modeling with the experimental data obtained, which made it possible to determine the heat transfer coefficient in the inter-tube space.

A large amount of computational work has been carried out on the study of the influence of geometric configurations of the properties of working bodies and the features of mathematical models on the thermal and hydraulic characteristics [6]. In experiments, visual results of comparing the coil heat exchange element with other types are obtained. The use of modern numerical modeling tools makes it possible to more fully describe physical processes, optimize design and technological solutions, and identify flow and heat transfer features [7].

The research of the Politecnico di Milano is worth mentioning. The research team of this institute develops new methods for burning [8,9], pyrolysis [10], chemical reactions [11] and the formation of vapors of various substances [12] related to heat power engineering. In addition, new information about the combustion kinetics has been obtained over the past five years. The works of the authors Alberto Cuoci et al. [8], Warumporn Pejpichestakul et al. [9], Alessandro Stagni et al. [10], Andrea Bassani et al. [11], and Guilia Bozzano et al. [12] have made a significant contribution to the development of world science.

The scientific developments of L. Rosenthal, conducted relatively recently, indicate that the theory of heat and mass transfer, especially evaporation, has its shortcomings in comparison with experimental studies of boiler units. L. Rosendahl and M. Mando presented the findings of their research in the form of the scientific work [13]. Researchers, for example, T. Asotani [14] and his colleagues, proposed a hypothesis of the behavior of a vapor-liquid mixture, and this conjecture was justified by the developed mathematical model, which is compatible with the outcomes of the studies performed by L. Rosendahl and M. Mando [13]. The hypotheses considered in the review were confirmed by the development of mathematical models. These patterns are well in accordance with each other, as well as with the fundamental physical rules, for example, the equations of conservation of mass and energy, as well as the boundary conditions of heat transfer processes.

\subsection{Purpose and Objectives of the Study}

The purpose of this study is to examine the process of evaporation of two-phase fluid in a closed system, in particular obtaining a mathematical model of the process of steam in the boiler coil based on the basis of analysis of the information obtained experimentally for oil and gas-fishery, and verification of theoretical and experimental data, reviewing the prospects for the optimization of a model steam boiler coil. 
The peculiarity of this study is to develop a methodological approach to solving problems of hydrodynamics in coils in mathematical modeling of the process of vaporization of a steam-water mixture in an indoor system using experimental data. Thanks to the use of variable values depending on the actual conditions, a scientific and experimental basis has been laid for further study of the design of direct-flow boilers.

\subsection{Use of Solar Collectors in a Steam Generator Set in the Summer}

There is an opportunity to use modern expensive technologies economically, especially since there are reasons for their strategic, economic and regulatory nature. It is important to understand that oil and gas fields in subarctic and arctic climate areas should adopt renewable energy trends.

In the foreseeable future, it is necessary to adequately restructure the energy balance so that renewable energy sources in the far north make up at least $20 \%$, which is necessary in hard-to-reach and remote regions.

In conjunction with the steam generator set, the authors used solar collectors for the heating (Figure 1) type and the air (Figure 2) type.

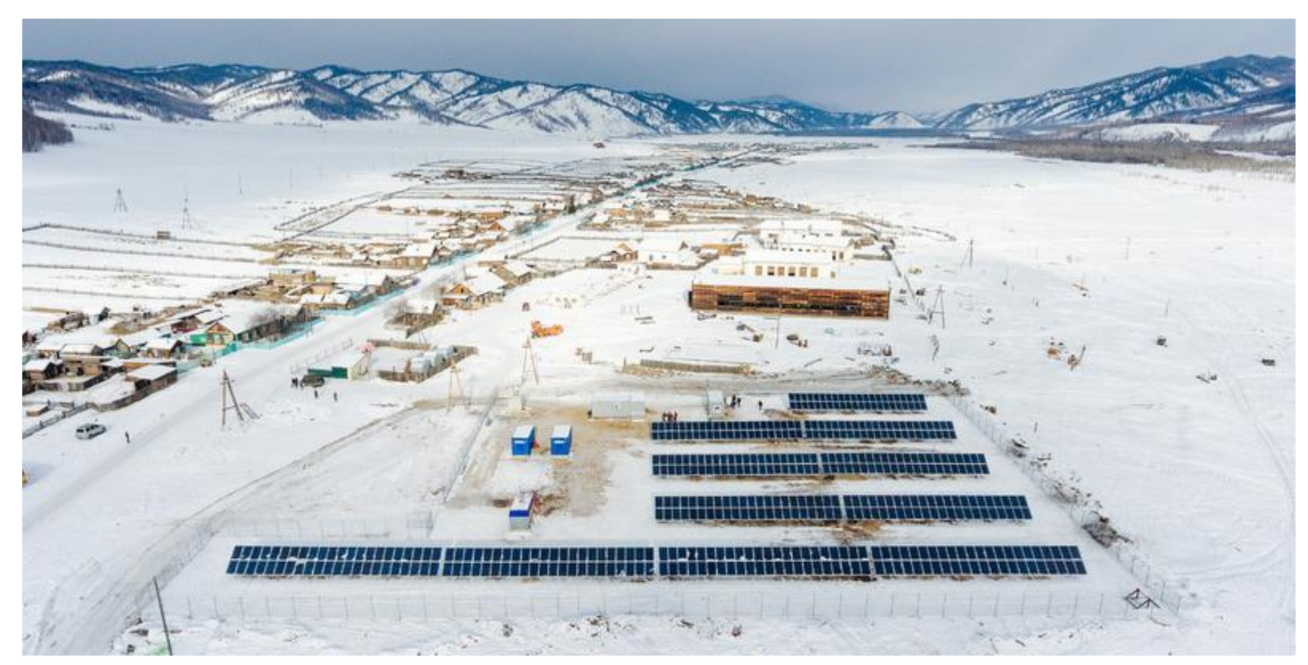

Figure 1. Application of solar collectors in the oil and gas field in subarctic conditions.

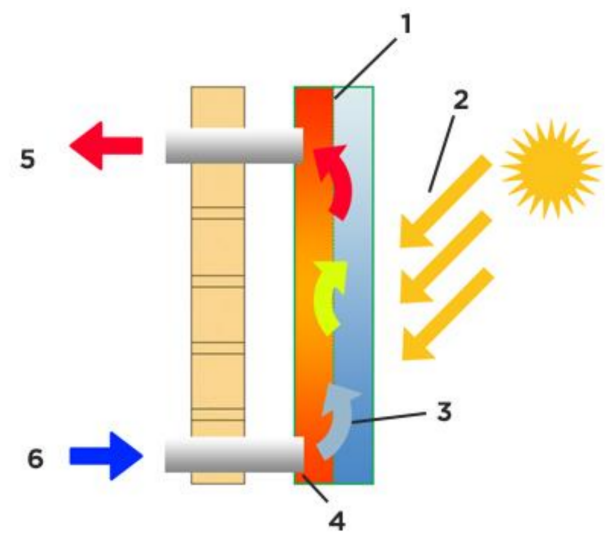

(a)

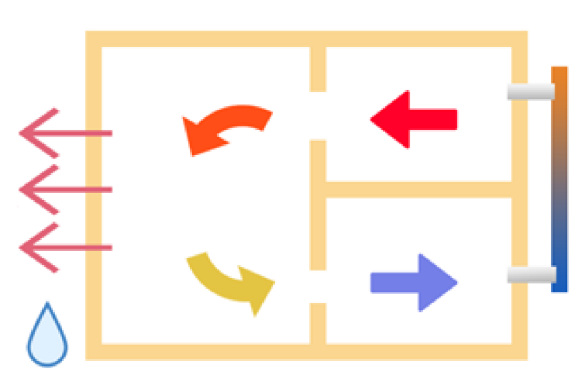

(b)

Figure 2. Application of air solar collectors in the oil and gas field in subarctic conditions: (a) scheme of air heating from solar radiation, (b) diagram of the movement of air mass in the room, 1-heated part of the solar collector, 2-incident solar radiation, 3-cold part of the solar collector, 4-air channel, 5-heated indoor air, 6-cold indoor air. 
The average annual energy input of direct solar radiation in the arctic varies from 2 to $4 \mathrm{~kW} / \mathrm{h}$ per square meter daily, and this is a very good indicator. For comparison, in the southern regions of Germany, it reaches $3.4 \mathrm{~kW} / \mathrm{h}$ per square meter daily. In Siberia, on clear summer days, the supply of solar energy can reach indicators of $6-8 \mathrm{~kW} / \mathrm{h}$ per square meter daily.

The sun's rays falling on the surface of the collector heat the helio-absorber, the fan is automatically started and cold fresh air from the street, or cooled from the room, passing through the helio-absorber is heated and transferred to the room displacing and replacing the cooled air mass.

There is a switch that can be used to turn off the solar collector when ventilation or heating is not required. In this case, the collectors heat and dry the room. With the help of a built-in fan, fresh street air passes through the filter, is heated in the solar collector and the heated air enters the room, displacing damp, cold, old air from the room.

\section{The Experimental Conditions}

A transportable boiler plant is common in hard-to-reach areas of the subarctic and arctic climate and is in demand in a variety of areas of our life: maintenance of private homes in towns and remote villages, in the field of production.

On drilling locales that specialize in oil extraction, steam and hot water are necessary for the technological and internal needs of the maintenance specialists.

The boiler plants have the required auxiliary equipment (water treatment equipment, boiler water supply system, fuel equipment, etc.), which currently requires repair, replacement, modification, since it is morally and physically outdated. The chemical water treatment system fails to handle tough, polluted water, putting boilers at danger and increasing the chance of failure due to tube pollution and damage.

One of the experimental components of the work involves the modernization of a transportable boiler plant by replacing the E-1.0-0.9 M (Z) boilers with direct-flow steam boilers of the coil type $[15,16]$. Preference is given to direct-flow boilers due to their suitable technical characteristics, compact size, ergonomics and low production and maintenance costs [17]. The experiment is designed to collect and analyze the performance characteristics of a steam boiler of the coil type in real conditions of the subarctic climate. For research purposes, the installation is situated on the locality of the Variogan oil area in preparation for the winter heating season.

The subarctic and arctic climates are observed in the regions of the far North, where the Northern Sea Route passes. But an important component is the ecology of the arctic, as a global value. In this case, in addition to the development of production and use of organic fuels, it is necessary to develop solar energy, and the sun can occupy a decent part of the energy supply by all indicators.

The number of difficulties in electricity and heat supply in subarctic and arctic zones is very large, ranging from the problem of fuel delivery and difficult navigation in a short time, and ending with a large proportion of organic fuel, wear and tear or lack of power lines in remote and hard-to-reach areas.

\section{Description of the Steam Plant}

A direct-flow steam boiler of the coil type is shown in Figures 3 and 4 . The principle of its operation is based on the complete evaporation of the liquid during its passage through the evaporation surface [18]. The coils of the steam boiler are coaxial cylinders. The working fluid evaporates in the course of a single stroke without re-circulation. The liquid moves along the coil. Since the process of vaporization occurs in the absence of a drum, there are no clear boundaries of vaporization in the coil. This process takes place in the total mass of the working medium $[19,20]$. 


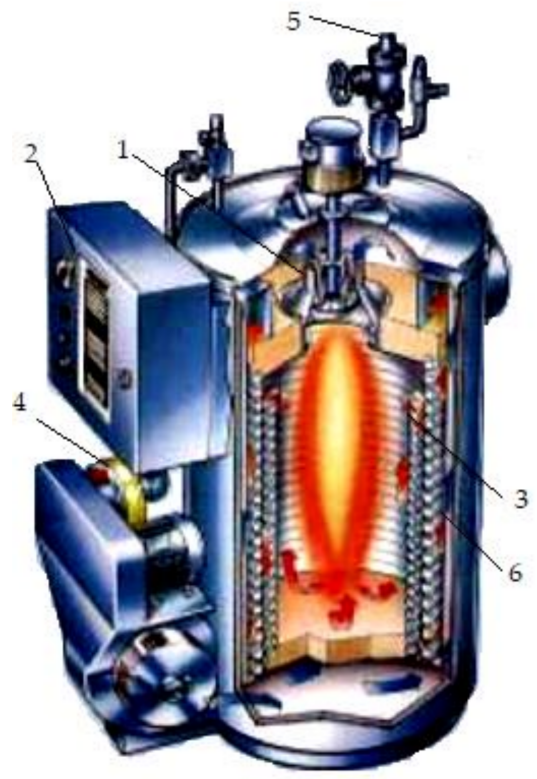

Figure 3. Direct-flow steam boiler device (appearance and cut of the boiler): 1-input camera, 2-control unit, 3-inner coil, 4-fan, 5-outlet valve, 6-external coil.

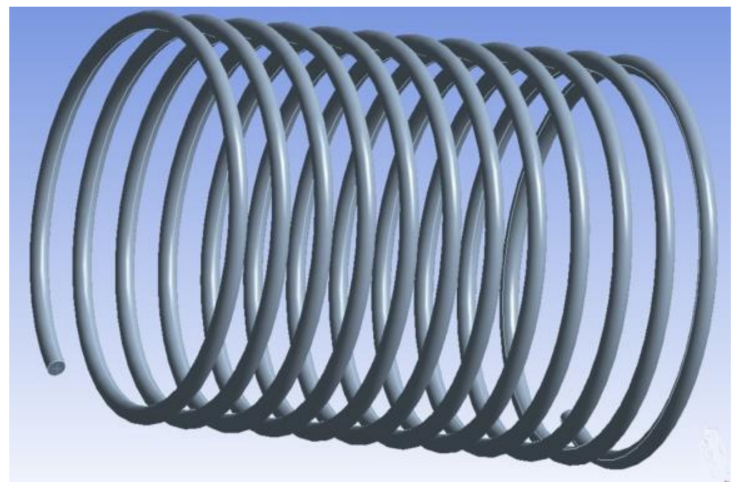

Figure 4. Coil of direct-flow steam boiler device.

The process of liquid evaporation in the coils of a steam boiler depends on many factors: the composition of the liquid, its volume, the influence of mass exchange and heat exchange processes, and so forth. Therefore, there are many approaches to its analysis, but there are no studies of the process of vaporization of multicomponent liquid in the coils of steam direct-flow boilers for indoor systems [21,22].

The experimental setup developed by the authors is shown in Figure 5.

The steam generator is installed in the research laboratory and is equipped with control systems, data collection on the main parameters. First of all, the flow rate (speed), pressure and temperature of the liquid, steam-water mixture, and superheated steam were measured.

Two steam generators are installed in the laboratory, the appearance of the laboratory corresponds to the type of block-modular transportable boiler house. It is these boilers that are most in demand in the subarctic climate in remote areas where oil and gas fields are located. The appearance of the block-modular boiler house, which is being developed by the authors, is shown in Figure 6. 


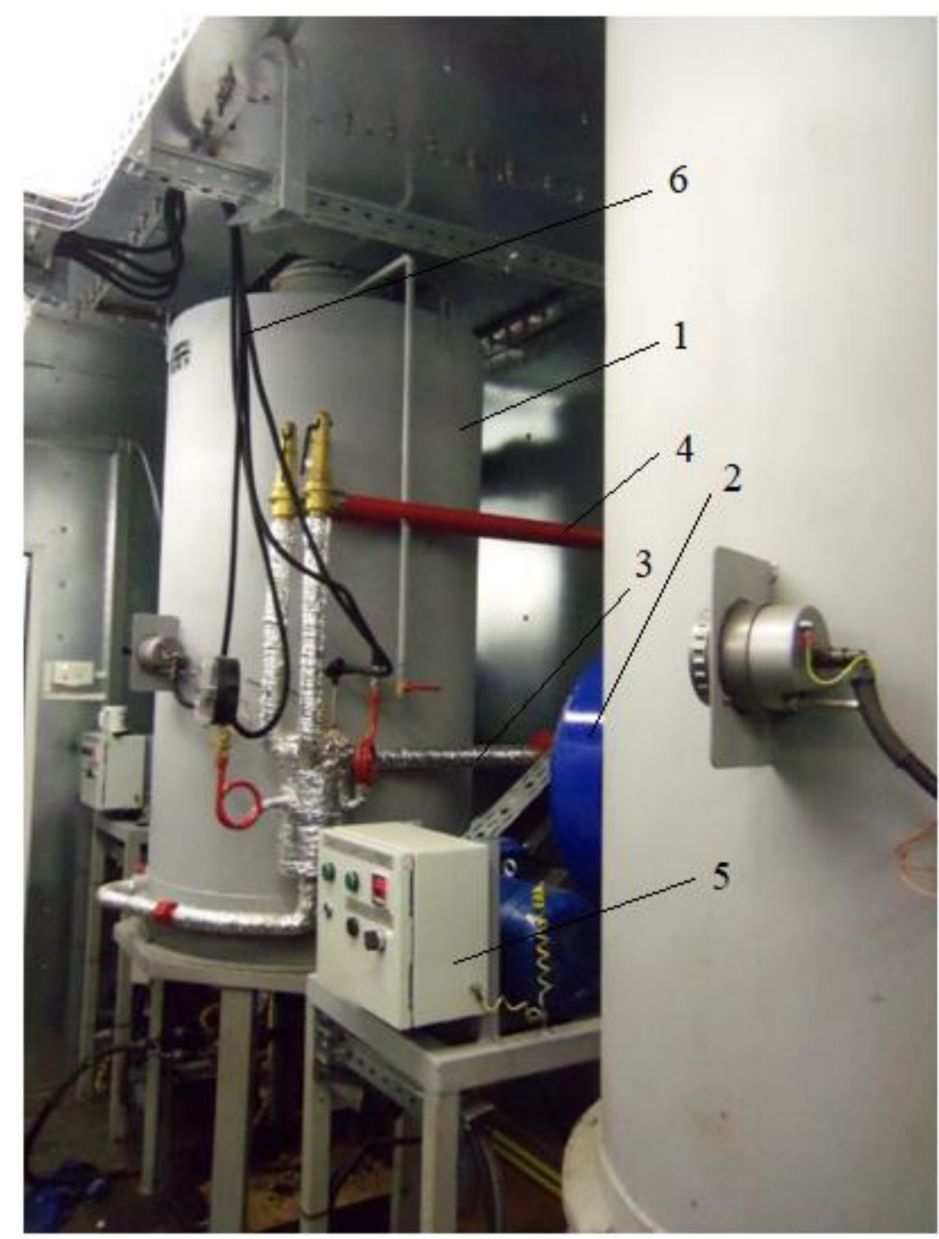

Figure 5. Research stand for the study of vapor formation and movement of liquid and steam in a steam generator of the coil type: 1 -the body of the steam generator, inside which the coils are located, 2-fan, 3-water supply pipeline, 4-pipeline of superheated steam obtained in, 5-control unit, 6-system for measuring the main parameters in the steam generator.

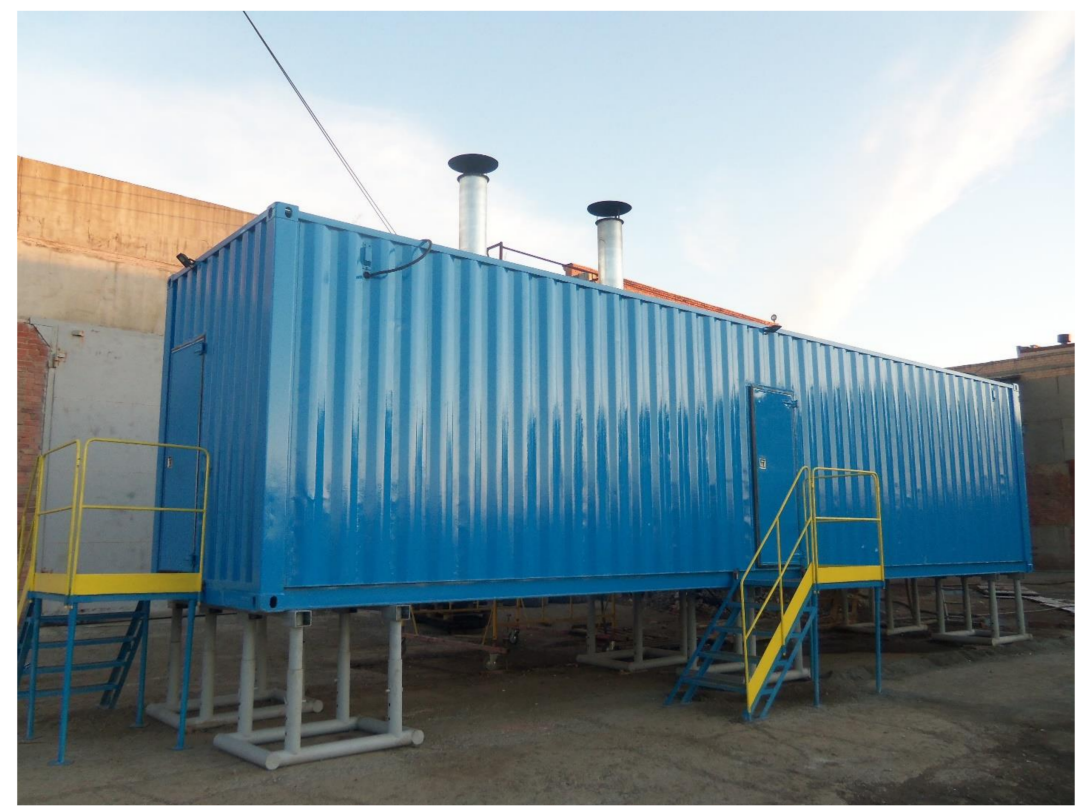

Figure 6. External view of a block-modular boiler house, with two coil-type steam generators installed inside, on which the research was carried out. 


\section{Theoretical Basis of the Study}

To study and illustrate the evaporation process in the coil, a mathematical pattern was prepared and imitated in the Ansys application [23-25]. To create the model, one needs to establish equations. So, the thermodynamic system formed during the passage in the coil was obtained. This system is considered heterogeneous, since it comprises of some physical homogeneous objects in the presence of discontinuities in the change of their characteristics inside the system. The gas and liquid mixture is the first phase-fluid, the second-vapor. When flowing in coils, the flow interacts with the channel wall due to friction and pressure, as well as heat-due to heat exchange with the wall. The intensity of the processes for gas-liquid mixtures depends on the flow structure, the phase distribution over the channel cross-section and internal processes [26-31].

Since there is an interface between the phases, such values as the concentration of components and the density of the mixture change abruptly at an infinitesimal point: the concentration is from 0 to 1 , and the density is from $\rho_{1}$ to $\rho_{2}$ [31,32]. So the density of the mixture can be given by the following Equation (1), which shows the density of the mixture:

$$
\rho_{\text {mix }}=\varphi_{1} \cdot \rho_{1}+\varphi_{2} \cdot \rho_{2},
$$

where $\varphi_{1}$ and $\varphi_{2}$-relative volume concentrations of components, which are continuous functions of time and coordinates; they are alternately zero and one.

It is accepted that a multicomponent liquid consists of one component and with a low concentration of all other substances. In this regard, the assumption of the absence of chemical reactions is introduced.

There are secondary circumstances that affect the development of the flow pattern, which depend on the flow rate of the phases, the positioning of the pipe and the phase formation.

Thus, some simplifications and assumptions were adopted for the construction of the mathematical model [32-35]:

- The one-dimensional problem statement was considered.

- The only mass the force of gravity.

- The forces of inertia are negligibly small.

- The differences in the pressure of the liquid and vapor phases of the flow were ignored.

- The differences in the temperature of the liquid and vapor phases of the flow were ignored.

- The flow modes for both phases are turbulent.

- The correlation coefficients differ little from the unit.

In this case, the correlation coefficients are assumed when determining the velocities and temperatures.

- Perturbations in the medium are considered smooth, not shock.

- No chemical reactions.

- The stratification of the liquid phase was not taken into account.

- Phase transformations-intensive.

To describe the turbulence, we used the standard k- $\varepsilon$ model with the introduction of new concepts-generation $P$ and dissipation $\varepsilon$. Two new equations allow us to consider turbulence in space and time. This model is semi-empirical and is based on a phenomenological approach and experimental results [36].

For simulation purposes, it is conventionally assumed that the transported gas-liquid mixture is a mixture of a Newtonian one-component viscous weakly compressible heatconducting liquid and a Newtonian one-component viscous compressible heat-conducting vapor.

To create the pattern, an "exact" gridline was applied. The thickening of the mesh is generated near the impervious walls [37]. 
If you select an arbitrary volume in the flow of a two-phase liquid $\tau$, which is bounded by the surface $\sigma$. Mass flow of the mixture through the surface $\sigma$ will be equal to the change in the mass of the mixture over time in the volume $\tau$ (Figure 7).

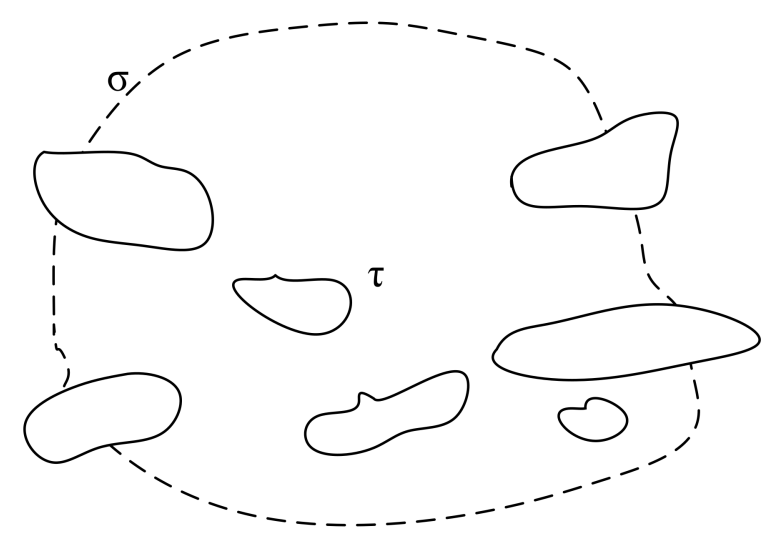

Figure 7. Flow of a two-phase liquid of any volume $\tau$, limited by the surface $\sigma$.

The general Equation (2) is valid for the flow of a mixture both in the presence of phase transformations of one component into another, and without them. This Equation (2) shows the unsteadiness of the vaporization process in the integral form:

$$
\frac{\partial}{\partial \mathrm{t}} \int_{\tau}\left(\varphi_{1} \cdot \rho_{1}+\varphi_{2} \cdot \rho_{2}\right) \mathrm{d} \tau+\int_{\sigma}\left(\varphi_{1} \cdot \rho_{1} \cdot\left(\omega_{1} \cdot d \sigma\right)+\varphi_{2} \cdot \rho_{2} \cdot\left(\omega_{2} \cdot d \sigma\right)=0 .\right.
$$

Equation (2) - the continuity equation. A two-phase liquid of arbitrary volume was isolated in the flow $\tau$, which is bounded by the surface $\sigma$ (Figure 5). Mass flow of the mixture through the surface $\sigma$ will be equal to the change in the mass of the mixture over time in the volume $\tau$. If the external normal to the surface is taken as the positive direction of the velocity $\sigma$, then arbitrary masses in time must have a minus sign. Hence, Equation (2) is obtained. It is general and valid for the flow of a mixture both in the presence of phase transformations of one component into another (liquid into gas or steam), and without them.

The carried-out studies, taking into consideration theoretical estimates and experimental facts, made it possible to construct a model of the vaporization process in coaxial cylinders.

Before creating the model, it was supposed that bubble boiling happens on the pipe surface in the boiler under discussion. The bubbles are then transferred to the main riverbed. As the fraction of steam rises, a plug is formed, which can take up the whole cross-section of the tube, and so the flow rate rises greatly. In this case, the boiling process can also happen on the wall. This operation can be replaced by a circular mode, when the tube wall is coated with a fluid film, and the middle section is populated by a vapor-water blend (Figure 6) [38].

When the boiling liquid moves in the pipes under consideration, which are close to the horizontal view, there is a stratification of the flow along the perimeter of the pipe. If the circulation rate and the vapor content in the flow are low, the two-phase flow is stratified into the vapor phase at the top of the tube and the fluid phase at the bottom.

With an increase in the velocity of circulation and vapor content, the crests of the liquid waves begin to touch the upper part of the pipe, then the flow passes into a kind of cork and finally — rod mode with an asymmetric distribution of the liquid and vapor phases (Figure 8). 


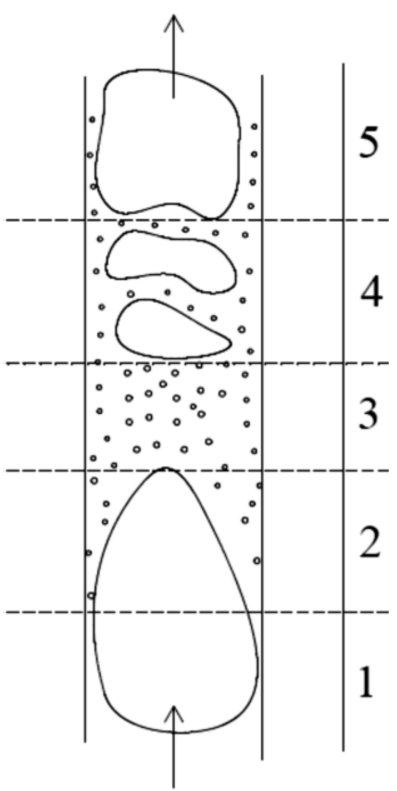

(a)
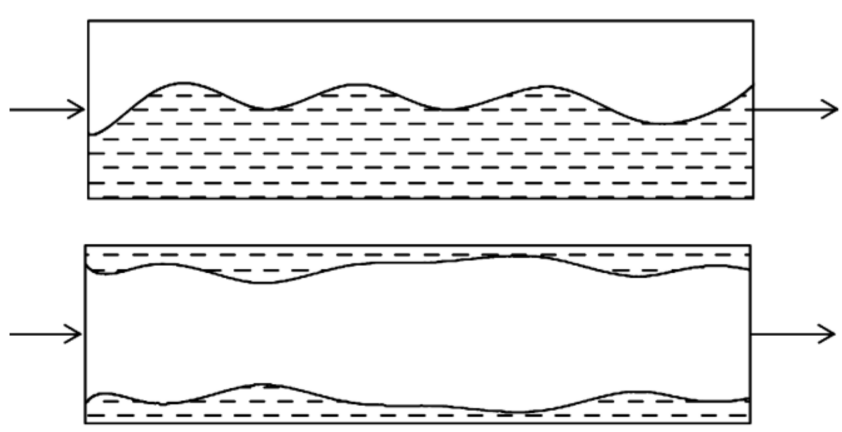

(b)

Figure 8. The process of vaporization in the coil: (a) vertical flow (1-water, 2 -nucleate boiling, 3-main flow, 4-plug mode, 5—steam), (b) horizontal flow.

According to the modeling and the resulting visualization, Figure 9 shows a grid superimposed on a solid-state coil model. In Figure 10, the coolant rate has reached its limit in the center of the pipe coil, which supports the abovementioned assumption.

The research data on the increase in the fuel combustion process led to the idea of using a direct-flow boiler model with coaxial coils in the boiler plant, because the air supply to the nozzle goes after heating in the air heater, which is built into the boiler and is a double casing. The air enters the jacket and is heated by the outgoing flue gases before entering the burner device. This type of construction shows good results in the intensification of the combustion process. It is worth noting that the design of convective surfaces made of a pipe looks like a ribbed surface, which serves as a good flue gas turbulator, due to which the heat exchange process is intensified.

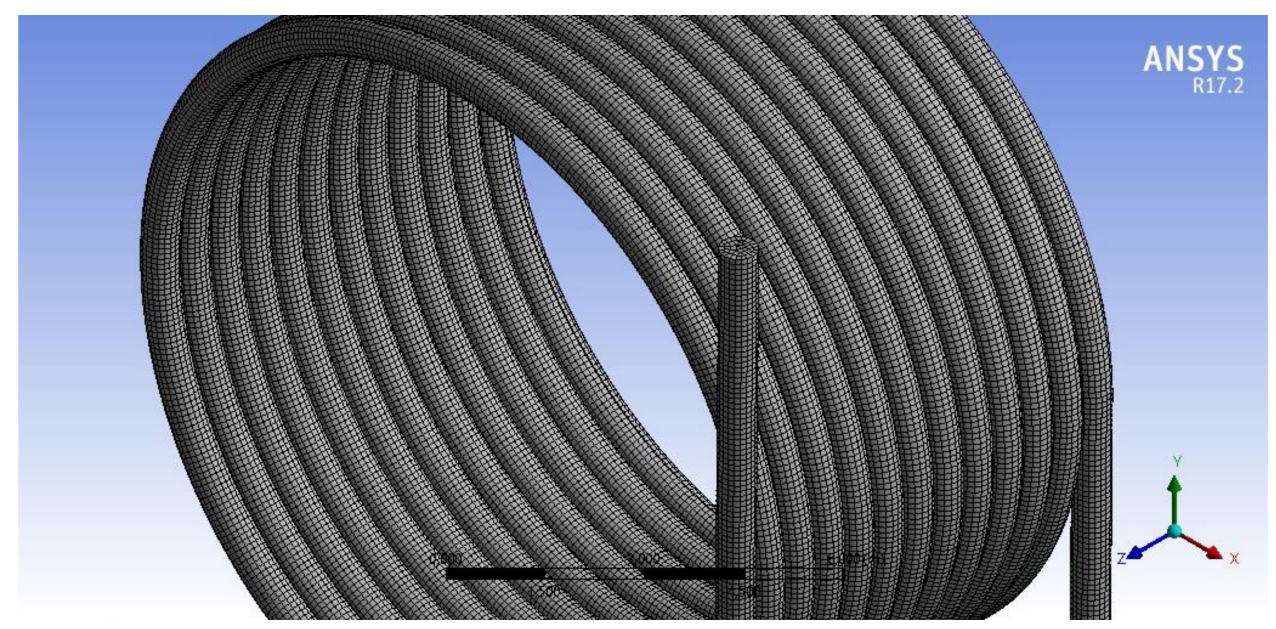

Figure 9. Mesh superimposed on a solid-state coil model. 

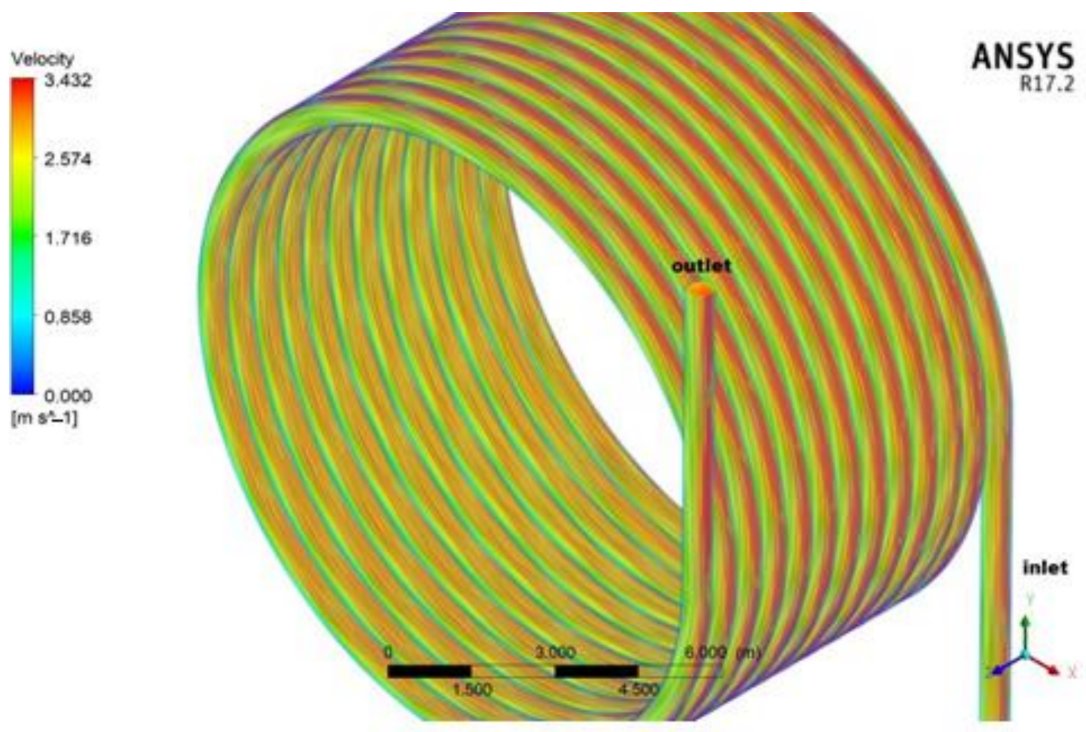

(a)
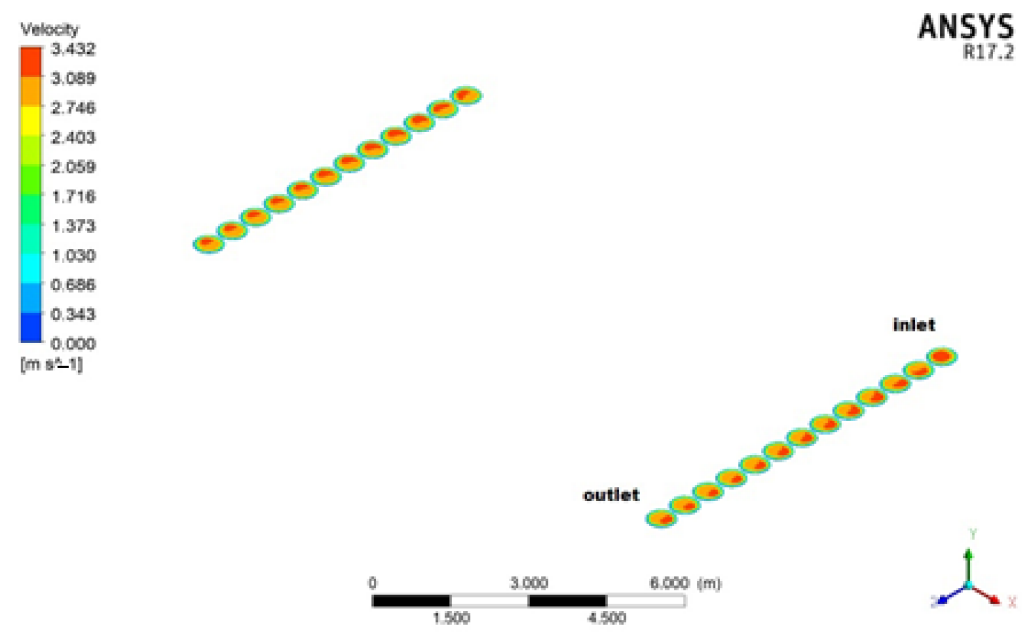

(b)

Figure 10. The simulation results, received in postprocessing: (a) velocity field in the coil, (b) the same velocity field in the coil, but in a horizontal section.

When creating a simulation of the vaporization procedure, the theory of boiling and vaporization modes in coils was validated. However, the study showed that there is a high probability of changing the latter mode to a dispersed one, when a vapor film forms near the wall, the thermal conductivity decreases, and, accordingly, the pipe wall can burn through if the density of the heat flow supplied to the coil is not reduced. The amount of heat that is released into the environment in the presence of external and internal factors (poor quality of the heat carrier, intense burning, wear of pipes) can serve as a catalyst and cause serious damage to the coils of the considered direct-flow boiler [39].

In this model, all the pipes of the outer coil are considered equivalent channels. Also for the inner coil. The channels are symmetrical. The boundary conditions are shown in the table. The initial conditions are assumed as follows - the temperature of the walls of the coils, the temperature of the media change from the entrance to the exit. The input and limit conditions are shown in Table 1. 
Table 1. Limit conditions.

\begin{tabular}{cc}
\hline Border & Boundary Condition \\
\hline Inlet & The medium enters the coil. Volume flow rate at the inlet. \\
$\begin{array}{c}\text { Outlet } \\
\text { of symmetry } \\
\text { Wall }\end{array}$ & The environment moves freely. Outlet pressure and velocity. \\
Symmetrical channels.
\end{tabular}

When creating a model, the accuracy of the grid construction is important. Meshing and modeling were performed in several versions of Ansys, versions 2017-2020. CFD modules were used. Next, in Figures 10 and 11, the results obtained by the authors in postprocessing are shown.
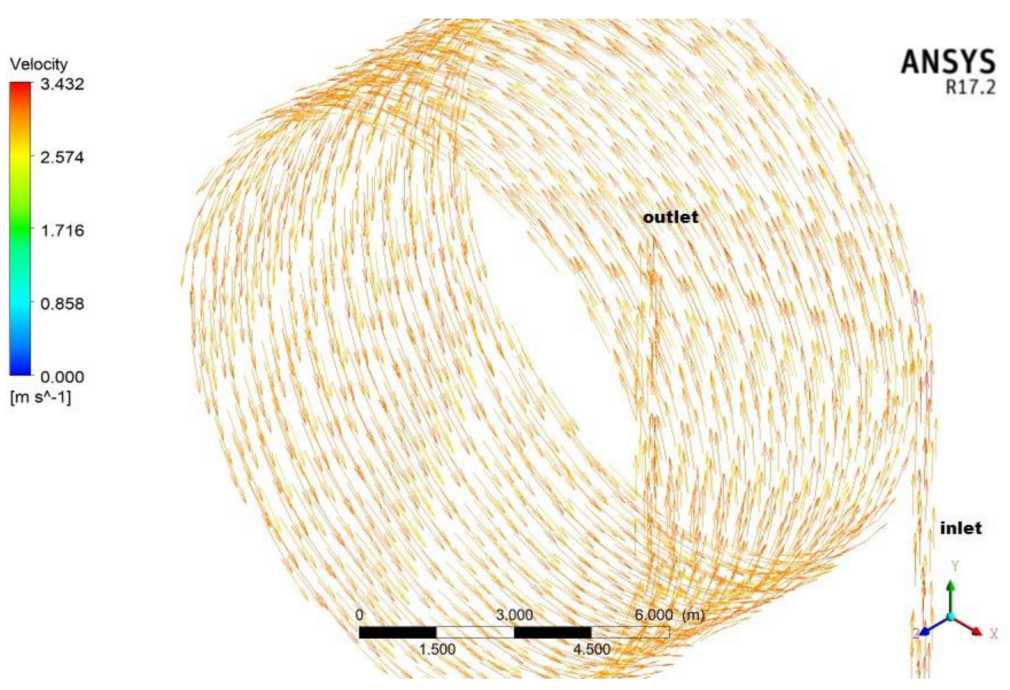

Figure 11. Vector velocity field in the coil obtained in postprocessing.

Figure 11 shows the vector velocity field in the coil, obtained by the authors in postprocessing. This vector field corresponds to Figures 9 and 10.

The modeling process in coils was considered in three stages-heating the water to the boiling point, vaporization in the steam-water mixture (assuming that the temperature of the mixture is constant and the perceived heat goes completely to the phase transition) and steam generation. Figures 10 and 11 show the distribution of the coolant velocity in the section of the coil at the time of heating from the flue gases at the second stage. According to the obtained model, it is possible to judge the process of growth of the vapor phase in the mixture, as well as the result of the flow movement. According to the above hypothesis and the resulting model, the formation of steam occurs in the immediate vicinity of the pipe wall but the vapor bubbles, breaking off as a result of movement under pressure, move to the central part of the pipe, forming a homogeneous structure that acquires a greater speed than the first phase. The velocity of the coolant in the maximum phase reached $3.549 \mathrm{~m} / \mathrm{s}$.

The mixture velocities at an infinitesimal point can be represented as the sum of (3). Similarly to Equation (1), the velocity of the mixture is determined as follows:

$$
\omega_{m i x}=\varphi_{1} \cdot \omega_{1}+\varphi_{2} \cdot \omega_{2}
$$

where $\varphi_{1}$ and $\varphi_{2}$ for a moment in time, still equal to zero and one.

On the interface of the phases $\omega_{1}=\omega_{2}$. Hence, the velocity vector of the mixture is a continuous function of time and coordinates and varies from $\omega_{2}$ to $\omega_{1}$, and its derivatives will undergo a discontinuity.

The relative volume concentrations can also be defined as parts of the total cross section of the elementary trickle of the mixture $\Delta S=\Delta S_{1}+\Delta S_{2}$. 
According to this definition, the velocities of the components of the mixture will be equal to (4) and (5). For individual flow sections, when the volume passing through these sections changes, the velocity is determined as follows:

$$
\begin{gathered}
\omega_{1}=\Delta V_{1} / \Delta S_{1}=\Delta V_{1} / \Delta S-\Delta S / \Delta S_{1}=\beta_{1} \cdot \omega_{\text {mix }} / \varphi_{1}, \\
\omega_{2}=\beta_{2} \cdot \omega_{\text {mix }} / \varphi_{2},
\end{gathered}
$$

where $\beta_{1}=\Delta V_{1} / \Delta V$ and $\beta_{2}=\Delta V_{2} / \Delta V$ 一the relative volume concentration of the components consumption.

If similar, the vector of the amount of motion, which we denote by $\rho_{c} \omega_{x}$, will be expressed as (6). The quantity is determined by the basic laws of physics:

$$
\rho_{c} \omega_{x}=\varphi_{1} \rho_{1} \omega_{1}+\varphi_{2} \rho_{2} \omega_{2},
$$

If the density of the mixture is understood as the density expressed by the formula (1), then the velocity of the mixture can be represented as (7). In Equation (6), the value of $\omega_{x}$ determined by the formula:

$$
\omega_{x}=x_{1} \omega_{1}+x_{2} \omega_{2},
$$

where $x_{1}$ and $x_{2}$-relative mass concentrations of components, alternately equal to zero and one.

Then from the Formulas (4)-(6) we get the ratio (8) between $\omega_{m i x}$ and $\omega_{x}$. Thus, after the transformations, we get the Equation (8):

$$
\omega_{x}=\rho_{\beta} \cdot \omega_{\text {mix }} / \rho_{\text {mix }},
$$

where $\rho_{\beta}$-the density of the mixture, calculated based on the volume flow of the components $\rho_{\beta}=\beta_{1} \rho_{1}+\beta_{2} \rho_{2}$. The volumetric flow concentrations are also alternately zero and one.

However, it should be taken into account that the object has the shape of coils (Figure 1). The outer and inner coils are made of pipes of different diameters. The outer coil is made of a pipe with a diameter of $28 \mathrm{~mm}$, the inner coil is made of a pipe with a diameter of $32 \mathrm{~mm}$. It is also worth taking into account that the diameter and height of the coaxial cylinders are different: the diameter of the outer cylinder is $890 \mathrm{~mm}$, the height is $1680 \mathrm{~mm}$, and the length of the pipe is $172.95 \mathrm{~m}$; for the inner coil, the dimensions are respectively diameter $-746 \mathrm{~mm}$, height $-1664 \mathrm{~mm}$ and pipe length $-119.52 \mathrm{~m}$.

In this regard, corrections to the coolant velocity for each type of coil are proposed, which are presented in the expression (9). This Equation (9) will be used to determine the flow rates in Equations (10)-(13):

$$
z_{i}=L_{i} \cdot d_{i} / H_{i} \cdot D_{i},
$$

where $H_{i}$-height of coil, $\mathrm{m} ; d_{i}$-the diameter of the coil, $\mathrm{m} ; L_{i}$-length of the coil, m; $D_{i}$ - the diameter of the cylinder, m.; $i$ - the coil is external or internal.

The calculation of the coolant velocity for the external coil, taking into account the expressions (4)-(7) and the correction (9), is performed according to the formulas (10) and (11), where $z_{i}$-correction for the velocity of the heat carrier by size for $i$-th coil:

$$
\begin{aligned}
& \omega_{1}^{\prime}=z_{i}^{1.25} \cdot \Delta V_{1}{ }^{\prime} / \Delta S_{1}{ }^{\prime}, \\
& \omega_{2}^{\prime}=z_{i}^{1.25} \cdot \Delta V_{2}{ }^{\prime} / \Delta S_{2}{ }^{\prime},
\end{aligned}
$$

Calculation of the velocity for the inner coil according to the Formulas (12) and (13). The resulting Equations (12) and (13) are similar in mathematical relations to Equations (10) and (11):

$$
\omega_{1}^{\prime \prime}=z_{i}^{0.5} \cdot \Delta V_{1}^{\prime \prime} / \Delta S_{1}^{\prime \prime},
$$




$$
\omega_{2}^{\prime \prime}=z_{i}^{0.5} \cdot \Delta V_{2}^{\prime \prime} / \Delta S_{2}{ }^{\prime \prime} .
$$

In Equations (10)-(13), the coefficients 1.25 and 0.5 are the powers that are calculated after analyzing and comparing experimental and theoretical data.

The experimental coefficient-expression (9)—and the adapted formulas for calculating the velocity in coils-Formulas (10)-(13) - were obtained for the first time and used for calculation taking into account the experimental values.

\section{Results and Discussion}

The authors carried out a series of tests on power steam generators. The temperature of water and steam, the flow rate, as well as a variety of additional parameters of the burning process were calculated.

These experimental results were compared with the data of computer simulations conducted by the authors.

\subsection{Results of Computer Simulation}

In addition, we present the results of modeling performed for coil heat exchangers, Figure 12. Figure 12a,b shows a model of the steam generation process in the coaxial cylinders of a direct-flow steam boiler of the coil type. Figure 8a is an image of the coil in the isometry. Figure $8 \mathrm{~b}$ shows the coils of the coil in the section. The figures show the process of heating the coolant-water as it passes through the outer coil: temperature $39.85^{\circ} \mathrm{C}$ corresponds to the beginning of the movement of the coolant at the entrance to the coil. Water temperature $371.126^{\circ} \mathrm{C}$ corresponds to the boundary between the outer and inner coil, where the water is then heated and enters to complete the vaporization process.

The model shows that the first two stages of the process in coils are considered-the heating of water to the beginning of boiling and the beginning of vaporization in the steam-water mixture. The ramjet boiler of the steam type is devoid of a drum, in which the process of completing steam formation clearly occurs. However, the created model illustrates the statement that the boundaries of vaporization in a direct-flow boiler can shift depending on the input parameters of the coolant, fuel and the design of the coil, but it is possible to simulate and understand the process of heating the coolant in direct-flow boilers. This will allow you to regulate steam generation in coils of different shapes at a higher quality level, with the lowest cost of all the resources used, and will also allow you to make adjustments to the design of the coil model in order to increase heat transfer and optimize the dimensions of the ramjet boiler in the future.

The flow of hot gases in the inter-tube space occurs in a wide range of Reynolds numbers $\left(\operatorname{Re}=600 \div 4 \times 10^{5}\right)$, the value of which is calculated from the diameter of the inlet and the gas parameters in the considered section.

The temperature fields in Figure $8 \mathrm{a}, \mathrm{b}$ are considered for the Reynolds number $\operatorname{Re}=1 \times 10^{5}$. This Reynolds value is chosen in connection with the assumption that the average value will allow for a more adequate assessment of the processes, since an increase in this parameter will make additional corrections for the amount of air and the flue gas flow rate, which in turn will exceed the heat transfer intensity.

During vaporization, the heat of the phase transition is absorbed, and during condensation, the heat of the phase transition is released, the value of which changes with the change in pressure. The value of the pressure change along the length of the pipe section was $0.2 \%$ per $1 \mathrm{~m}$ of the pipe length. At a fixed pressure, the saturated liquid and the saturated vapor have the same temperature. During vaporization, the temperature of the steam does not differ from the temperature of boiling water, and during condensation, the temperature of the resulting condensate is equal to the temperature of the steam. In order to maintain boiling, it is necessary to supply heat not to heat the liquid, but to turn it into steam.

The results of modeling confirm the possibility of steam formation on different coils of the coil, depending on the amount of heat supplied, as well as on the conditions of the vaporization process, namely, pressure and temperature. 


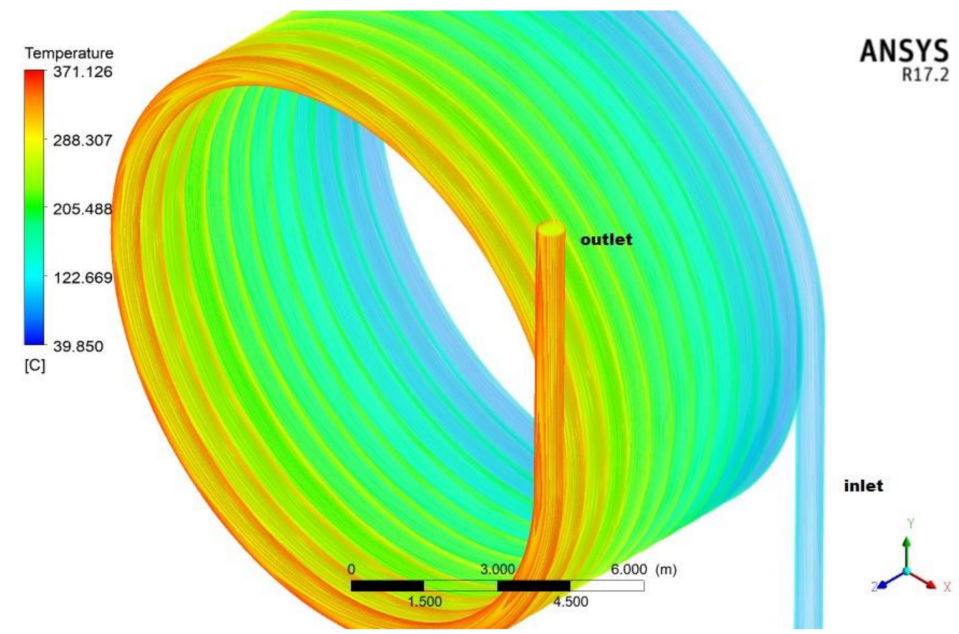

(a)

ANSYS

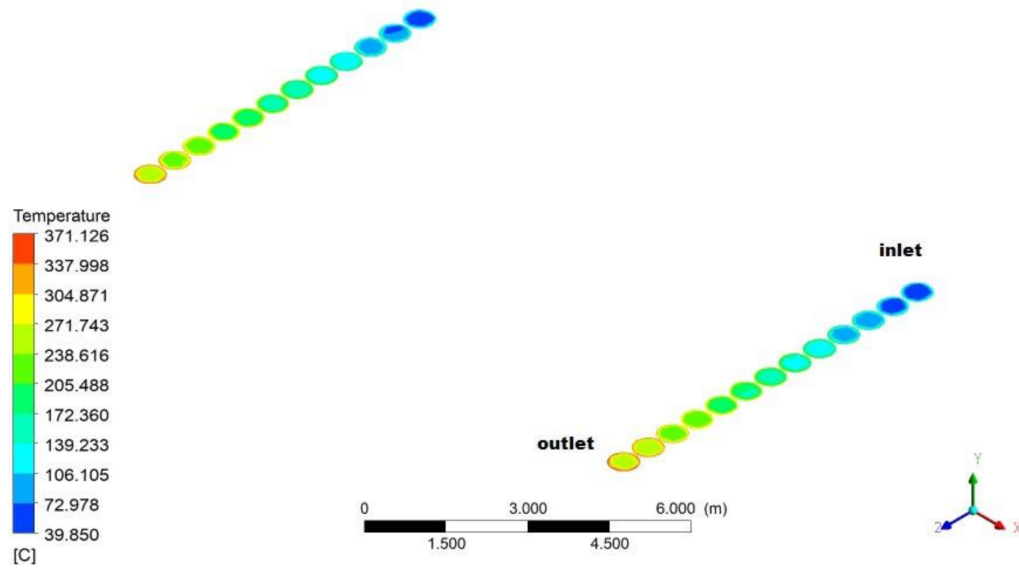

(b)

Figure 12. Model of the steam formation process in the coil: (a) change in the flow temperature of the water-steam mixture in the steam generator coil along the flow path, (b) section of the coil with a moving steam-water mixture (scaling relative to the drawing (a)).

As shown below, in experiments on a coil steam generator operating in an oil and gas field, a significant amount of heat is consumed during boiling and vaporization, in addition, small-diameter coils have a noticeable hydraulic resistance. But in the end, superheated steam is formed in the steam generator.

\subsection{Comparison of Experimental Data and Simulation Data}

The experiment was conducted in order to obtain experimental data (temperature, coolant velocity) of the operation of a direct-flow boiler of the coil type and further analysis. The information obtained will allow us to assess the scientific potential for further modernization of the plant.

The work was carried out in real conditions at the Severnoye field during the heating season. The parameters were measured during the operational and commissioning tests of the boiler plant. During the start-up of the boiler, the variables were: the volume flow rate of the coolant in the range from 0.7 to 1 ton per hour, the amount of fuel supplied varied in the setting range from 80 to $100 \%$.

The experiment was carried out in real conditions during the operational and commissioning tests of the boiler plant. The flow rate of the coolant is set at 1 ton per hour, the 
time of the experiment is $30 \mathrm{~min}$, the share of the channel cross-section is 0.9 of the internal cross-section, taking into account the contamination of the snake.

Using a thermocouple measured the temperature of the steam info for steam computed tables of thermodynamic properties of water and steam flow rate is fixed according to the Karat-520 flow meter.

On the basis of the obtained data, the mixture velocities were calculated according to the Formulas (4)-(7), (10) and (11). All initial and calculated values are shown in Table 2.

Table 2. Comparison of vapor phase velocities based on theoretical and experimental data for the external coil.

\begin{tabular}{cccccc}
\hline No. & Temperature & Steam Density & Consumption & $\begin{array}{c}\text { Velocity } \\
\text { (Experiment) }\end{array}$ & Velocity (Theory) \\
\cline { 2 - 6 } & $\boldsymbol{T},{ }^{\circ} \mathbf{C}$ & $\boldsymbol{\rho}, \mathbf{~ k g} / \mathbf{m}^{\mathbf{3}}$ & $\boldsymbol{\Delta} \boldsymbol{V}, \mathbf{~ m}^{\mathbf{3}} / \mathbf{s}$ & $\boldsymbol{\omega}_{\text {exp }}, \mathbf{m} / \mathbf{s}$ & $\boldsymbol{\omega}_{\text {th }}, \mathbf{m} / \mathbf{s}$ \\
\hline 1 & 115 & 0.964 & 0.288 & 1.945 & 1.751 \\
2 & 120 & 1.120 & 0.248 & 2.261 & 2.035 \\
3 & 118 & 1.056 & 0.263 & 2.130 & 1.923 \\
4 & 119 & 1.091 & 0.255 & 2.200 & 1.978 \\
5 & 120 & 1.120 & 0.248 & 2.261 & 2.035 \\
6 & 116 & 1.002 & 0.277 & 2.010 & 1.808 \\
7 & 117 & 1.032 & 0.269 & 2.072 & 1.860 \\
8 & 118 & 1.056 & 0.263 & 2.130 & 1.923 \\
9 & 120 & 1.120 & 0.248 & 2.261 & 2.035 \\
10 & 119 & 1.091 & 0.255 & 2.200 & 1.978 \\
\hline
\end{tabular}

\subsection{Data Processing}

The distribution laws for the obtained velocity values are considered, according to which it is assumed that the values have a normal distribution with the parameters $\alpha$ and $\sigma^{2}$, if the probability density is described by the expression (14). Equation (14) is standard, but transformed for experimental conditions:

$$
f(x)=(\sigma x \sqrt{2 \pi})^{-1} \exp \left[-(\ln x-\alpha)^{2} / 2 \sigma^{2}\right], x>0
$$

Graphs of the density distribution for experimental and theoretical values are shown in Figure 13.

When constructing the histogram, intervals of equal length were plotted along the abscissa axis, into which the entire range of possible values of the value $x$ was divided, and the frequencies $n \_x / n$ were displayed along the ordinate axis. The height of each bar of the histogram is equal to the corresponding frequency. Thus, we obtained an approximate representation of the law of probability distribution for a random variable $\mathrm{x}$ in the form of a step function, the approximation of which to the curve $f(x)$ will give the density of the distribution.

The resulting graphs are presented with an offset to the right. The errors calculated for descriptive data statistics are 0.035 and 0.028 for experimental and theoretical data, which allows us to conclude that the velocity change is best described by the proposed model. According to the results of the analysis, the volume costs and the parameters of the coil have the greatest influence. This should be taken into account when designing and upgrading the coils.

The parameters were calculated using data sensitivity analysis, data validation was performed by repeated tests, uncertainty was detected when using the instruments, as well as the total extended uncertainty, the upper and lower limit of uncertainty for each measured parameter. 


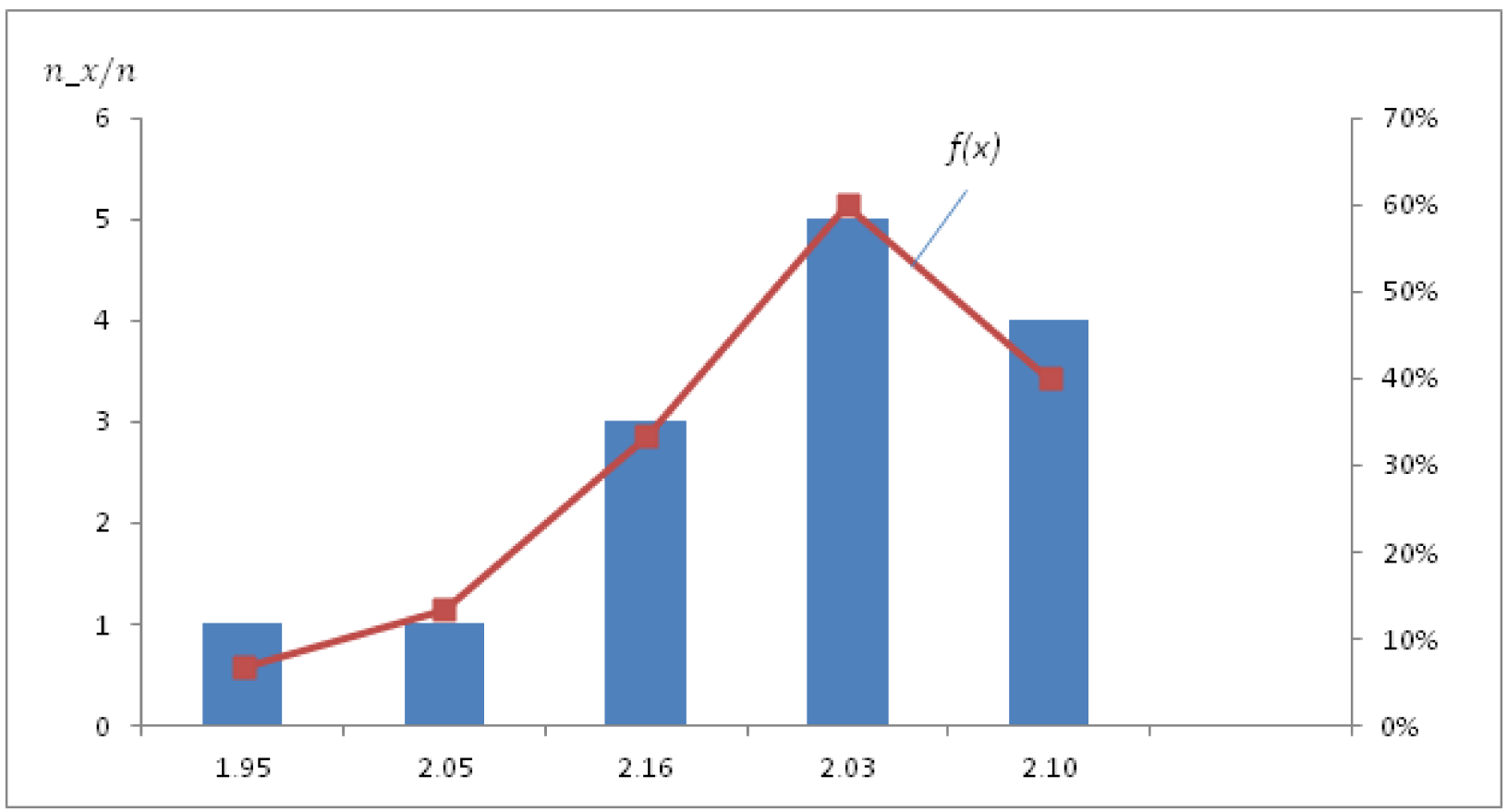

(a)

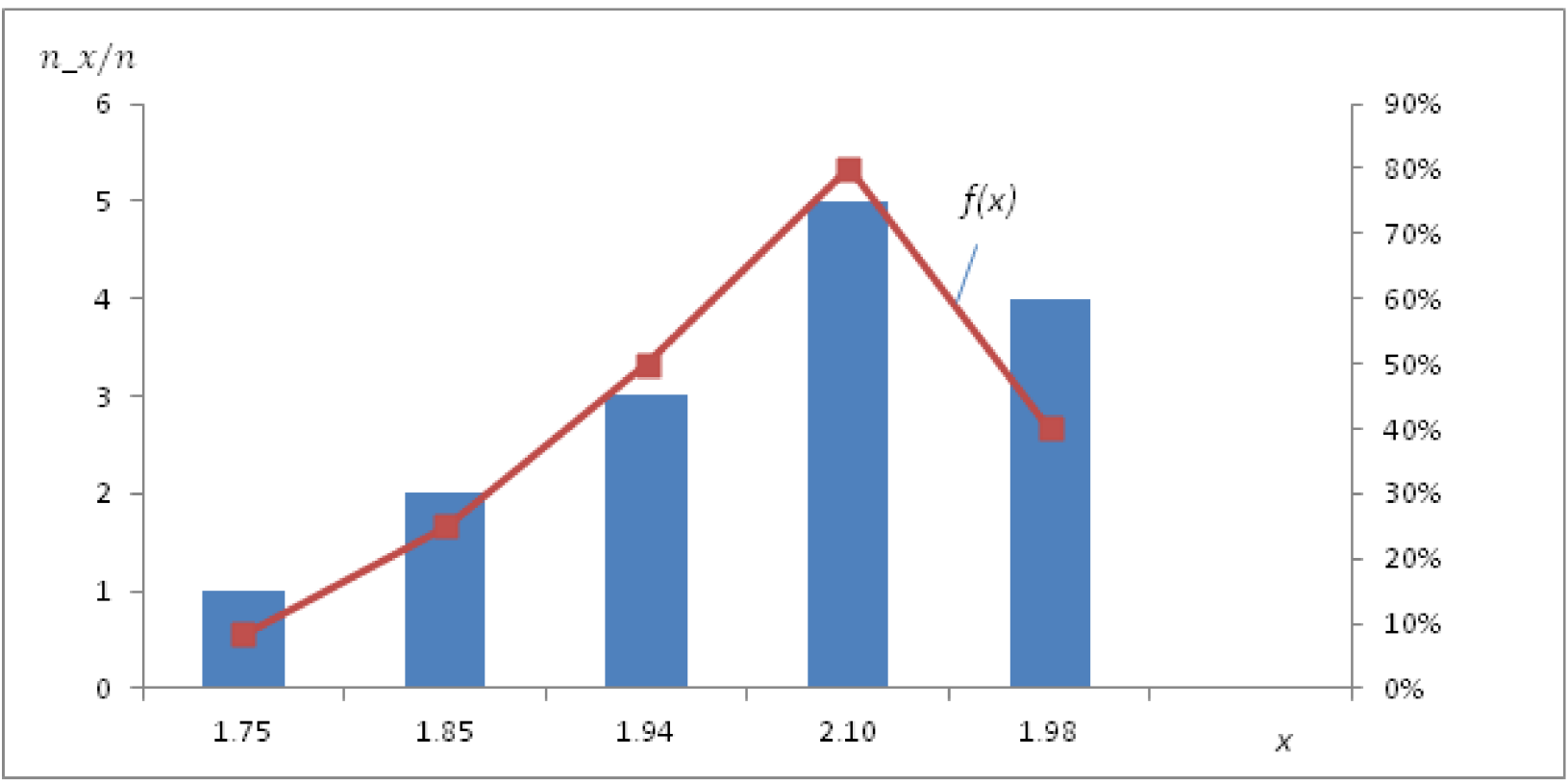

(b)

Figure 13. The histogram and the equalizing density of the distribution of the obtained values during the analytical calculation and experiment (the values in the sample are the steam velocities): (a) processing of the sample data in the analytical calculation, (b) processing of the sample data of the experiment.

Here is the result of validating the temperature data (Figure 14).

In their studies [38], the authors considered similar points, but when burning fuel. In addition, it was assumed in [39] that the most basic thermodynamic functions can be used as the basis of the methodology. In the study [40], the direction of analysis laid down in [38] was partially continued. Finally, similar methods of thermodynamic analysis were used in [41-43]. 


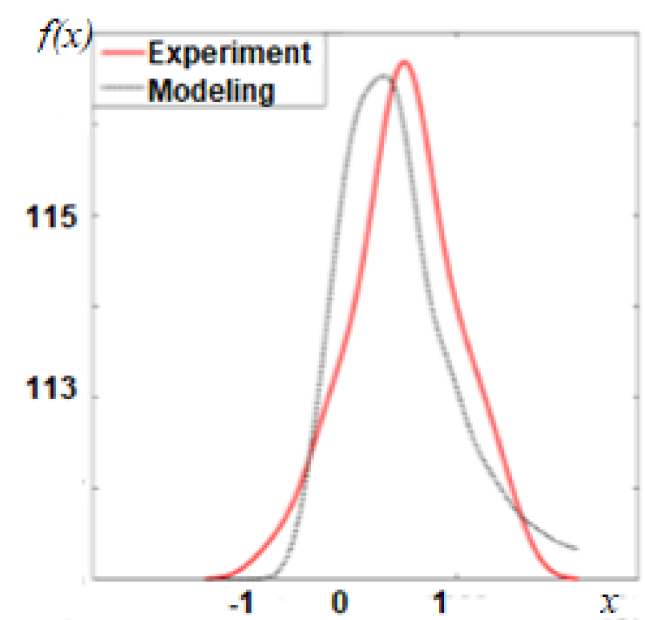

Figure 14. Normal distribution of the probability density of the temperature (lognormal).

The temperature of the coolant was measured under the conditions of a theoretical and real experiment. The results are collected as a sample of values. Next, the sample is processed and the results are shown in the Figure 10. Theoretical values (Modeling) and the experimental data obtained a more lognormal distribution. The obtained graphs allow us to state that the distribution is logarithmically normal. Values that are far from the average indicate the sensitivity of the steam boiler during regime adjustment, the susceptibility of the process of heat exchange and vaporization in the coils from the initial temperature of the coolant, from the fuel consumption, from the volume flow of the coolant. It should be noted that the time of the experiment indicates a rapid exit of the boiler to the stabilization mode. The criteria of agreement, based on the established law of distribution, make it possible to establish that the discrepancy between the theoretical and empirical frequencies can be considered insignificant.

\subsection{Uncertainty and Validation}

The obtained research results should be checked for the correctness of the data obtained, namely, to calculate the uncertainty. In addition, it is necessary to validate the measurement methodology.

The authors emphasized in their work that such curves can be constructed in the operation of industrial steam generators.

Calculate the arithmetic mean of the temperature of the steam from all measurements at a given point:

$$
T=\frac{1}{n} \sum_{i=1}^{n} T_{i} .
$$

After calculating the Formula (15), we get the value $T=393 \mathrm{~K}$.

For sources of random uncertainty, we calculate the uncertainty by type $A$ :

$$
u_{A}(T)=\sqrt{\sum_{i=1}^{n}\left(T_{i}-T\right) /(n(n-1))} .
$$

Calculations using the Formula (15) gave the result $u_{A}(w)=0.8 \%$.

For sources of systematic uncertainty (instrument error) calculating the uncertainty by type $B$ :

$$
u_{B}(T)=\frac{\Delta T}{\sqrt{3}}
$$

Calculations using the Formula (17) showed the value of $u_{B}(T)=1.58 \%$. 
Calculate the total standard uncertainty:

$$
u_{C}(T)=\sqrt{u_{A}(T)^{2}+u_{B}(T)^{2}} .
$$

Using the Formula (18), get the value $u_{C}(T)=\sqrt{0.64+2.4964}=1.771 \%$.

For the confidence probability (coverage probability) $P=0.95$ (recommended in the Manual calculation of uncertainty) specify the coverage factor $k=2$ and calculate the extended measurement uncertainty:

$$
u=k u_{C}(T) .
$$

We obtain that the uncertainty is $3.542 \%$. According to the norms of the Customs Agreement of the countries of the Eurasian Economic Union, the uncertainty limit when working with high-pressure units is 5\%.

Validation of the methodology was carried out in the software package Matlab. Validation is shown on Figures 15 and 16, with Error $=201.5694$ (Normal), Error $=139.3117$ (Lognormal). The graphs are made in Matlab.

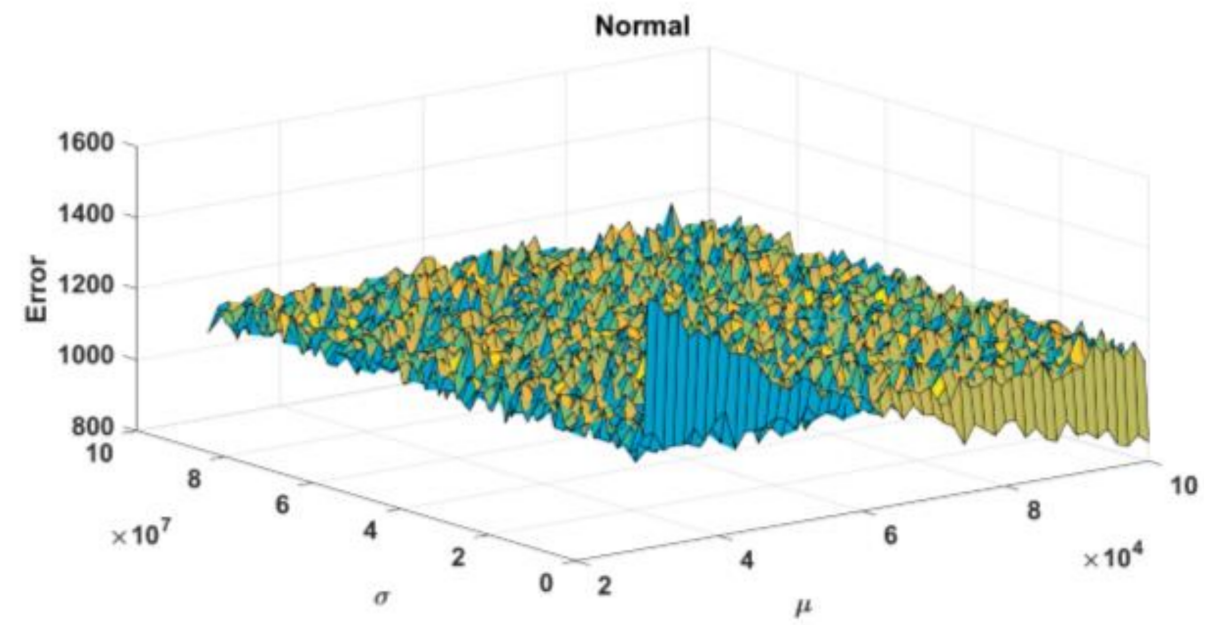

Figure 15. Validation error (Normal): Error-error value, $\sigma$-sample variance, $\mu$-sample mathematical expectation.

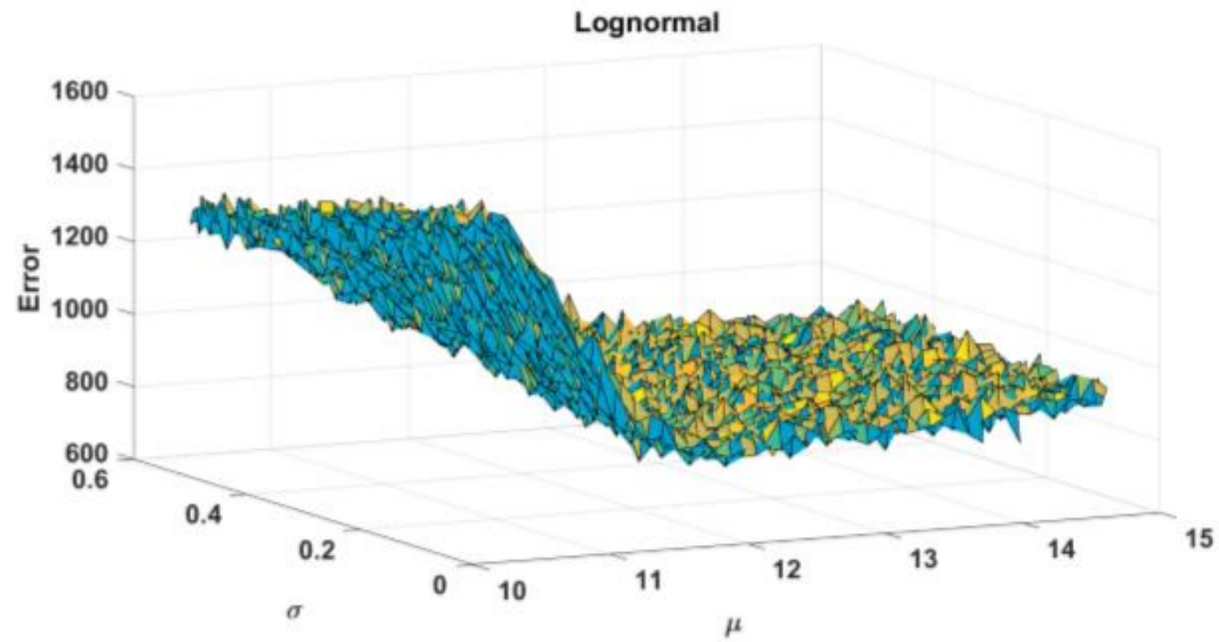

Figure 16. Validation error (Lognormal): Error - the value of the error, $\sigma$ - the sample variance, $\mu$-sample mathematical expectation. 
These Figures 15 and 16 show the error value defined as Normal in Figure 15 and Lognormal in Figure 16. The values in these figures are dimensionless and represent: Error-the error value, $\sigma$-the sample variance, $\mu$-the sample mathematical expectation.

\subsection{Improving the Efficiency and Reliability of the Steam Generator Set}

When working on the development of a mathematical simulation of the evaporation process, the theory of simmering and vaporization operation in coils was verified. An experimental study demonstrated that there is a high probability of changing the latter mode to a dispersed one, when a vapor film forms near the wall, the thermal conductivity decreases and, accordingly, the pipe wall can burn through, if the density of the heat flow supplied to the coil is not reduced. The amount of heat that is released into the surrounding environment in the existence of inner and outermost factors: low quality of the coolant, intense combustion, fraying of the pipes, can act as an accelerant and cause significant damage to the coils of the direct-flow boiler.

The conducted experimental studies led to a change in the operating modes of the steam generator set. The simulation made it possible to visualize the process of vaporization in a coil-type steam generator. Similar research results were published by scientists from different countries. Let's compare the data obtained.

Scientific developments of E. V. Mikhaylenko, carried out relatively recently, show that the theory of heat and mass transfer, in particular the movement of flows of liquids, has its drawbacks as applied to experimental studies of boiler installations. E. V. Mikhaylenko presented the research results in the form of a developed model [16]. A. Bruce-Konuah et al. in the work [44] consider the issues of energy saving in boiler installations and heat supply systems at residential facilities, and also point out the shortcomings of hot water boiler units. D. Dixon and A. Nguyen in their work [45] studied forecasting algorithms, models of hot water and steam production systems, and these authors came to the conclusion that there are opportunities to optimize the design of boilers and heat supply systems. I. Kusumastuti et al. in the work [46] considered the processes of vaporization and injection of condensate into steam to change its parameters and came to the conclusion that the systems of vaporization and steam supply require improvement.

In the works of Vinous Hameed, Fatima J. Hamad [20] and Edward Boje [21], mathematical models applicable to the hydrodynamics of boiler units of similar designs are proposed.

In the work of Marcin Trojan [22], the author proposes a non-standard mathematical model applicable to a steam generator.

In [26] K. A. Orlov, A. A. Alexandrov, V. F. Ochkov, A.V. Ochkov offer a whole software package for calculating the hydrodynamics of a boiler unit.

All mentioned works have their drawbacks and their benefits. Since the boiler unit examined in this article is unique, it is hard to make an exact match based on the results of research of design and models. The authors of this article, develop specific mathematic models that are applicable to a new class of vapor generator.

Let's compare the data obtained by different authors, for example, on the hydrodynamics of water in a boiler unit, Table 3 .

Table 3. Comparison of the experimental data of the authors at a temperature of $120^{\circ} \mathrm{C}$.

\begin{tabular}{cccc}
\hline $\begin{array}{c}\text { Velocity } \\
\text { (Experiment), m/s }\end{array}$ & $\begin{array}{c}\text { According to } \\
\text { the Authors }\end{array}$ & $\begin{array}{c}\text { According to the Data } \\
\text { of K. A. Orlov et al. [16] }\end{array}$ & $\begin{array}{c}\text { According to the Data } \\
\text { of V. Hameed et al. [20] }\end{array}$ \\
\hline $\mathrm{w}$ & 2.26 & 2.41 & 2.34 \\
\hline
\end{tabular}

\section{Conclusions}

The values of the velocities of the coolant in the coils, obtained theoretically and experimentally, differ little in magnitude and are described by a single distribution law, it follows that the calculation formulas and the entered coefficients can be used to calculate the velocities for coils of a similar design. 
A dependence is assumed for this type of coil design, which is reflected in the effect of the increase in the Reynolds number on the heat transfer intensity, due to an increase in the flue gas flow rate and a decrease in the temperature difference at the inlet and outlet.

The experimental data underwent sensitivity analysis, including an uncertainty band, and the methodology was validated. Data from experiments and simulations are compared with the results of other authors.

Increasing the initial parameters of the coolant due to preheating from solar energy will allow you to make adjustments to fuel consumption, in the dimensions of the coil, allowing you to reduce the design of the coil.

Thus, there are prospects for the modernization of the coil by reducing the initial parameters of the coolant and installing additional elements with the participation of solar panels, or by intensifying the heat exchange between the flue gases and the coolant through the walls of the coil.

The prospects for the operation of direct-flow boilers of the serpentine type are primarily related to the spread of their applicability to the complex conditions of industrial enterprises and drilling rigs located in subarctic climate areas. Based on the results of the experimental work carried out, it is possible to outline the trend of using such installations in the Arctic climate.

The principle of the operation of such installations should be extended to heat exchange devices in various areas of industrial production, such as chemical and agricultural. In such enterprises, coil-type heat exchangers are really required, and the set of experimental data obtained and the developed test methodology can be used as a basis for new scientific research.

When evaluating the operation of the steam generator set as a whole, it should be noted that the thermal efficiency in the summer period is increased due to the use of solar radiation, as well as a decrease in the impact on the environment, which is important for the forest-tundra zone of the subarctic climate zone. Thus, the authors' developments solve not only technical and economic issues, but also climate issues, and also have an active action to prevent climate change.

Author Contributions: Conceptualization, K.O., S.A. and S.K.; Data curation, K.O., S.A. and S.K.; Formal analysis, K.O. and S.A.; Investigation, K.O., S.A. and S.K.; Methodology, K.O., S.A. and S.K.; Project administration, K.O.; Supervision, K.O., S.A. and S.K.; Validation, K.O., S.A. and S.K.; Visualization, K.O. and S.K.; Writing-original draft, K.O., S.A. and S.K.; Writing-review \& editing, K.O., S.A. and S.K. All of the authors contributed significantly to the completion of this manuscript, conceiving and designing the research, writing and improving the paper. All authors have read and agreed to the published version of the manuscript.

Funding: This research received no external funding.

Institutional Review Board Statement: Not applicable.

Informed Consent Statement: Not applicable.

Data Availability Statement: The data presented in this study are available on request from the corresponding author.

Conflicts of Interest: The authors declare no conflict of interest.

\section{Nomenclature}

$\rho_{\text {mix }} \quad$ is the density of the mixture, $\mathrm{kg} / \mathrm{m}^{3}$.

$\rho_{1}$ and $\rho_{2}$ are density of components, $\mathrm{kg} / \mathrm{m}^{3}$.

$\varphi_{1}$ and $\varphi_{2}$ are relative volume concentrations of components, which are continuous functions of

$\varphi_{1}$ time and coordinates; they are alternately zero and one;

$\mathrm{T} \quad$ is an arbitrary volume, $\mathrm{m}^{3}$

$\sigma \quad$ is the surface; 


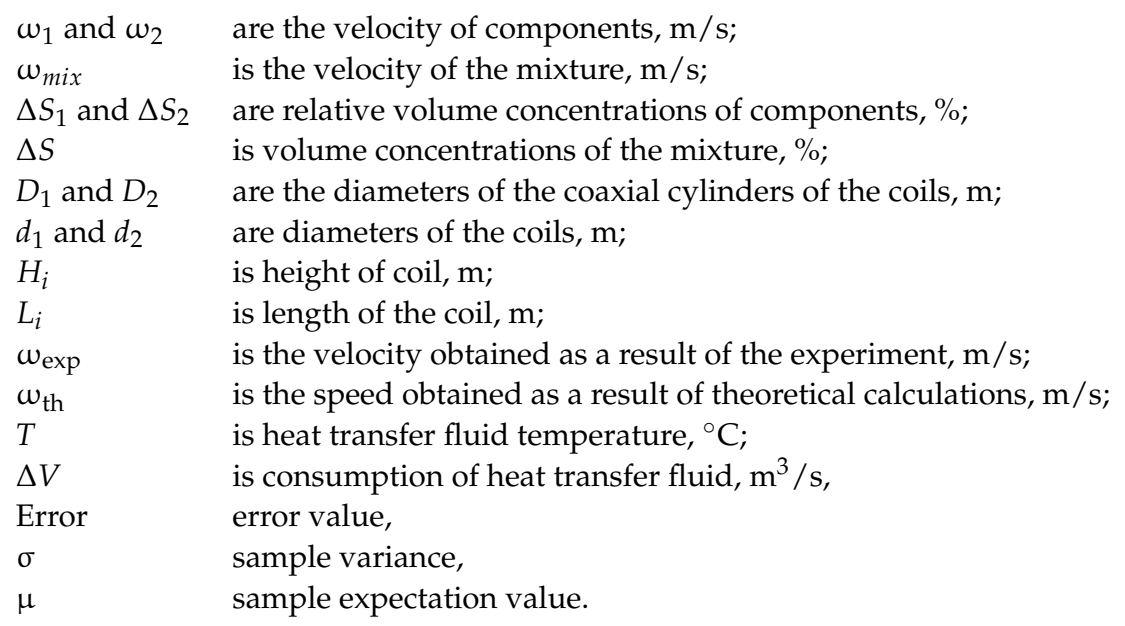

\section{References}

1. Solonin, V.I.; Satin, A.A. Modeling of heat transfer in a coil heat exchanger in relation to the Uniterm reactor installation, Nauka i obrazovanie: Nauchnoe izdanie MSTU im. n. e. Bauman. Sci. J. 2014, 10, 398-412.

2. Naphon, P. Thermal performance and pressure drop of the helical-coil heat exchangers with and without helically crimped fins. Int. Commun. Heat Mass Transf. 2007, 34, 321-330. [CrossRef]

3. Naphon, P.; Wongwises, S. A review of flow and heat transfer characteristics in curved tubes. Renew. Sustain. Energy Rev. 2006, 10, 463-490. [CrossRef]

4. Jayakumar, J.S.; Mahajani, S.M.; Mandal, J.C.; Vijayan, P.K.; Bhoi, R. Experimental and CFD estimation of heat transfer in helically coiled heat exchangers. Chem. Eng. Res. Des. 2008, 86, 221-232. [CrossRef]

5. Alexandrov, V.Y.; Koroleva, A.P.; Kukshinov, N.V.; Frenchov, M.S. Numerical modeling of heat transfer and determination of thermal and hydraulic characteristics in a bench heat exchanger of a serpentine type, Izvestiya vysshikh uchebnykh zavedeniy. Mech. Eng. 2017, 11, 79-88.

6. Prabhanjan, D.G.; Raghavan, G.S.V.; Rennie, T.J. Comparison of heat transfer rates between a straight tube heat exchanger and a helically coiled heat exchanger. Int. Commun. Heat Mass Transf. 2002, 29, 185-191. [CrossRef]

7. Lopukhov, S.A.; Frenchov, M.S. Computational study of thermal and hydraulic characteristics in a model coil heat exchanger. In Proceedings of the Seventh Russian National Conference on Heat Exchange; MEI: Moscow, Russia, 2018; pp. $202-204$.

8. Cuoci, A.; Frassoldati, A.; Faravelli, T.; Ranzi, E. A computational tool for the detailed kinetic modeling of laminar flames: Application to $\mathrm{C} 2 \mathrm{H} 4 / \mathrm{CH} 4$ coflow flames. Combust. Flame 2013. [CrossRef]

9. Pejpichestakul, W.; Ranzi, E.; Pelucchi, M.; Frassoldati, A.; Cuoci, A.; Parente, A.; Faravelli, T. Examination of a soot model in premixed laminar flames at fuel-rich condition. Proc. Combust. Inst. 2019, 37, 1013-1021. [CrossRef]

10. Stagni, A.; Calabria, R.; Frassoldati, A.; Cuoci, A.; Faravelli, T.; Chiariello, F.; Massoli, P. Kinetic Modeling of the Ignition of Droplets of Fast Pyrolysis Bio-oil: Effect of Initial Diameter and Fuel Composition. Ind. Eng. Chem. Res. 2021. [CrossRef]

11. Bassani, A.; Bozzano, G.; Pirola, C.; Frau, C.; Pettinau, A.; Maggio, E.; Ranzi, E.; Manenti, F. Sulfur Rich Coal Gasification and Low Impact Methanol Production. J. Sustain. Dev. Energy Water Environ. Syst. 2018, 6, 210-226. [CrossRef]

12. Bozzano, G.; Dente, M. Single bubble and drop motion modeling. Chem. Eng. Trans. 2009, 17, 567-572. [CrossRef]

13. Asotani, T.; Yamashita, T.; Tominaga, H.; Uesugi, Y.; Itaya, Y.; Mori, S. Prediction of ignition behavior in a tangentially fired pulverized coal boiler using CFD. Fuel 2008, 87, 482-490. [CrossRef]

14. Mandø, M.; Rosendahl, L.; Yin, C.; Sørensen, H. Pulverized straw combustion in a low-NOx multifuel burner: Modeling the transition from coal to straw. Fuel 2010, 89, 3051-3062. [CrossRef]

15. Zykov, A.K. (Ed.) Steam and Hot Water Boilers: A Reference Manual; Energoatomizdat: Moscow, Russia, 1987; 128p.

16. Mikhailenko, E.V. (Ed.) How to Improve the Characteristics of Mobile Steam Generators; Glavny Energetik: Dmitrov, Russia, 2015; Volume 5-6, pp. 65-71.

17. Kuts, R.V. Analysis of the design of a small-sized steam boiler with forced circulation, Excellence in the design and operation of marine vessels and structures. In Collection of Reports of the XII Student Interuniversity Scientific and Technical Conference; Kuts, R.V., Ocheretyany, V.A., Eds.; Sevastopol State University-Publishing House: Sevastopol, Russia, 2017; pp. 71-74.

18. Direct-Flow Boiler: Pat. RU168311U1. Russian Federation No. 2016111789; Claimed 29.03.2016; Published 30.01.2017. Byul. No. 4. 7p. Available online: https:/ / patents.google.com/patent/RU168311U1/en (accessed on 10 March 2021).

19. Zilberberg, Y.A. Mobile Boiler Plant: Pat. RU2246661C1. Russian Federation No. 2003119493/06, Claimed 01.07.2003; Published 20.02.2005. Byul. No. 5. 10p. Available online: https:// patentimages.storage.googleapis.com/d3/1b/83/4837b0c9ecafb5/RU224 6661C1.pdf (accessed on 10 March 2021).

20. Hameed, V.M.; Hamad, F.J. Investigation study of vertical helical coil heat exchanger. In AIP Conference Proceedings; AIP Publishing LLC.: College Park, MA, USA, 2020; Volume 2213, p. 020093.

21. Boje, E. Dry-out point estimation in once through boilers. IFAC Proc. Vol. 2009, 42, 723-728. [CrossRef] 
22. Trojan, M. Modeling of a steam boiler operation using the boiler non-linear mathematical model. Energy 2019, 175, 1194-1208. [CrossRef]

23. Dudkin, M.M. Experimental Study of the Operation of a Snake-Type Steam Boiler in Operation at the Northern Oil Field; Series: Power Engineering; Dudkin, M.M., Osintsev, K.V., Kuskarbekova, S.I., Eds.; South Ural State University: Chelyabinsk, Russia, 2019; Chapter 4; Volume 19, pp. 14-25.

24. Kuznetsov, N.V. Thermal Calculation of Boilers (Normative Method), 3rd ed.; Reprint and Add; NPO TsKTI: St. Petersburg, Russia, 1998; 259p.

25. Roddatis, K.F. Handbook of Small-Scale Boiler Installations; Roddatis, K.F., Poltaretsky, A.N., Eds.; Energoatomizdat: Moscow, Russia, 1989; 488p.

26. Suslov, V.A. (Ed.) Heat and Mass Transfer: A Textbook, 3rd ed.; Reprint and Add; GOU VPO SPbGTURP: St. Petersburg, Russia, 2008; $120 p$.

27. Ivanova, G.M. Heat Engineering Measurements and Devices: Textbook for Universities, 2nd ed.; Rev. and Add; Ivanova, G.M., Kuznetsov, N.D., Chistyakov, V.S.-M., Eds.; Moscow Power Engineering Institute: Moscow, Russia, 2005; 460p.

28. Boyko, E.A. Structural Characteristics of Power Generating Units: A Reference Guide for Course and Diploma Design of Students; Boyko, E.A., Okhorzina, T.I., Eds.; KSTU: Krasnoyarsk, Russia, 2003; 223p.

29. Mukhachev, G.A. (Ed.) Thermodynamics of Steam-Gas Mixtures: Textbook; Kazan State Technical University: Kazan, Russia, $1995 ; 67 p$.

30. Fraňa, K.; Attia, S.; Stiller, J. A Bubble Formation in the Two-Phase System. In International Conference on Computational Science; Springer: Cham, Switzerland, 2019; pp. 580-586.

31. Seleznev, V.E. Methods for Constructing Flow Models in Main Pipelines and Channels; Seleznev, V.E., Pryalov, S.N.-M., Eds.; Uneditorialurss: Moscow, Russia, 2012; 560p.

32. Lin, Y.; Li, J.; Chen, Z.; Li, W.; Ke, Z.; Ke, H. Two-Phase Flow Heat Transfer in Micro-Fin Tubes. Heat Transf. Eng. 2019, 42, 369-386. [CrossRef]

33. Ghajar, A.J. (Ed.) Non-Boiling Two-Phase Heat Transfer. In Two-Phase Gas-Liquid Flow in Pipes with Different Orientations; Springer Briefs in Applied Sciences and Technology; Springer: Cham, Switzerland, 2020; pp. 103-116.

34. Ren, T.; Mu, H.; Liu, S.; Sun, Y.; Zhang, J.; Liu, S. Prediction of gas-liquid two-phase heat transfer coefficient. Appl. Therm. Eng. 2017, 116, 217-232. [CrossRef]

35. Korkodinov, Y.A. (Ed.) Review of the family of k- $\varepsilon$ models for modeling turbulence. In Bulletin of the Perm National Research Polytechnic University; Series: Mechanical Engineering, Materials Science; Perm National Research Polytechnic University: Perm, Russia, 2013; Chapter 2; Volume 15C, pp. 5-16.

36. Shabliy, L.S. Computer Modeling of Typical Hydraulic and Gas-Dynamic Processes of Engines and Power Plants in Ansys Fluent: Textbook; Shabliy, L.S., Krivtsov, A.V., Kolmakova, D.A., Eds.; Samar Publishing House: Samara, Russia, 2017; 108p.

37. Saurel, R.; Boivin, P.; Le Métayer, O. A general formulation for cavitating, boiling and evapo-rating flows. Comput. Fluids 2016, 128, 53-64. [CrossRef]

38. Toropov, E.; Osintsev, K.; Aliukov, S. New Theoretical and Methodological Approaches to the Study of Heat Transfer in Coal Dust Combustion. Energies 2019, 12, 136. [CrossRef]

39. Toropov, E.V.; Osintsev, K.V.; Aliukov, S.V. Analysis of the calculated and experimental dependencies of the combustion of coal dust on the basis of a new methodological base of theoretical studies of heat exchange processes. Int. J. Heat Tech. 2018, 36, 1240-1248. [CrossRef]

40. Osintsev, K.; Aliukov, S.; Prikhodko, Y. New Methods for Control System Signal Sampling in Neural Networks of Power Facilities. IEEE Access 2020, 8, 192857-192866. [CrossRef]

41. Aliukov, S.; Osintsev, K. Mathematical Modeling of Coal Dust Screening by Means of Sieve Analysis and Coal Dust Combustion Based on New Methods of Piece-Linear Function Approximation. App. Sci. 2021, 11, 1609. [CrossRef]

42. Osintsev, K.; Aliukov, S.; Kuskarbekova, S. Experimental Study of a Coil Type Steam Boiler Operated on an Oil Field in the Subarctic Continental Climate. Energies 2021, 14, 1004. [CrossRef]

43. Osintsev, K.; Aliukov, S.; Prikhodko, Y. A Case study of Exergy Losses of a Ground Heat Pump and Photovoltaic Cells System and Their Optimization. Energies 2021, 14, 2077. [CrossRef]

44. Bruce-Konuah, A.; Jones, R.; Fuertes, A.; Wilde, P. Central Heating Settings in Low Energy Social Housing in the United Kingdom. Energy Procedia 2019, 158, 3399-3404. [CrossRef]

45. Dixon, D. An Empirical Oil, Steam, and Produced-Water Forecasting Model for Steam-Assisted Gravity Drainage with Linear Steam-Chamber Geometry. SPE Reserv. Eval. Eng. 2019, 22, 1615-1629. [CrossRef]

46. Kusumastuti, I.; Erfando, T.; Hidayat, F. Effects of Various Steam Flooding Injection Patterns and Steam Quality to Recovery Factor. J. Earth Energy Eng. 2019, 8, 33-39. [CrossRef] 